\section{A internacionalização no Ensino Superior pelos letramentos acadêmicos: uma perspectiva necessária}

Maria Izabel Rodrigues Tognato

Maria Izabel Rodrigues Tognato

Universidade Estadual do Paraná - Campo Mourão, PR, Brasil.

E-mail: belinhatognato@hotmail.com ORCID: 0000-0003-3705-0354
Resumo: Este estudo trata da necessidade e da relevância social dos letramentos acadêmicos no Ensino Superior, objetivando promover uma discussão acerca de iniciativas de ensino e pesquisa, como práticas letradas, envolvendo línguas estrangeiras, com vistas à internacionalização. Trata-se de um dos princípios desta Universidade, conforme Plano de Desenvolvimento Institucional (PDI) proposto pela Universidade Estadual do Paraná, no Brasil. Quanto à metodologia, analisamos as produções de escrita e reescrita de professores em formação, de um curso de Letras (Português/Inglês), com foco no gênero de texto Abstract e seus elementos constitutivos tomando por base as capacidades de linguagem apresentadas pela Escola de Genebra. Os resultados apontam para avanços neste processo de estudo e de produção de texto pelos estudantes, visando a uma compreensão mais ampliada dos letramentos acadêmicos considerando-se aspectos relacionados à internacionalização.

Palavras-chave: Internacionalização; Ensino Superior; Letramentos acadêmicos; Práticas letradas. 


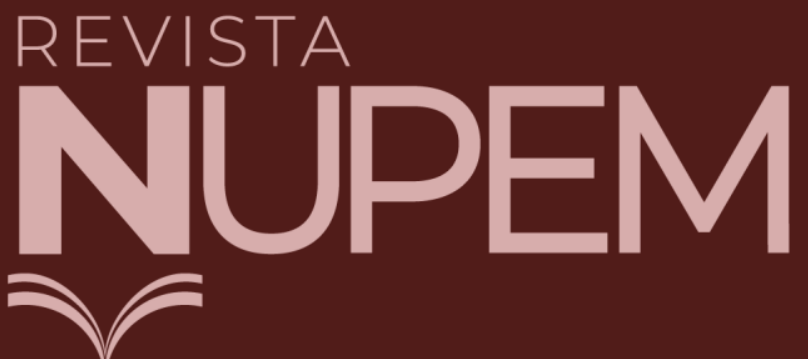

Revista NUPEM, Campo Mourão, v. 13, n. 28, p. 159-176, jan./abr. 2021

\section{Internationalization in Higher Education through academic literacy: a necessary perspective}

\section{La internacionalización en la Enseñanza Superior por el letramento académico: una perspectiva necesaria}

Abstract: This study deals with the need and the social relevance of academic literacies in Higher Education seeking to promoting a discussion about teaching and research initiatives as training practices, as literate practices, involving foreign languages with a view to internationalization. This is one of our University's principles, according to the Institutional Development Plan (PDI) which is a document proposed by the State University of Paraná, in Brazil. As for the methodology, we analyzed the future teachers' written and rewritten productions from a course of Letters (Portuguese/English), focusing on the text genre Abstract and its constituent elements based on the language capacities presented by Geneva School. The results point to advances in this process of study and text production by the students, aiming at a broader understanding of academic literacies considering aspects related to internationalization.

Keywords: Internationalization; Higher Education; Academic literacy; Literate practices.
Resumen: Este estudio se basa en la necesidad de discutir el letramento académico en la Enseñanza Superior con el objetivo de promover una discusión acerca de las iniciativas de enseñanza e investigación como prácticas formativas e letradas que involucran lenguas extranjeras, con atención a la internacionalización. Este es uno de los principios de esta Universidad, de acuerdo con el Plan de Desarrollo Institucional (PDI) que es un documento propuesto por la Universidad del Estado de Paraná, en Brasil. En cuanto a la metodología, evaluamos las producciones de escritura y rescritura de profesores en formación, de la carrera de Letras (Portugués/Inglés), con atención al género de texto Abstract y sus elementos constitutivos basados en las capacidades de lenguaje presentado por la escuela de Ginebra. Los resultados apuntan para los avances en ese proceso de estudio y producción de texto por parte de los estudiantes con el fin de obtener una comprensión más amplia de la alfabetización académica en lo que se consideran los aspectos relacionados con la internacionalización.

Palabras clave: Internacionalización; Enseñanza Superior; Alfabetización académica; prácticas letradas. 


\section{Introdução ${ }^{1}$}

Tomamos a internacionalização como um aspecto relevante em nossos estudos, uma vez que é considerada uma ação essencial que integra o Plano de Desenvolvimento Institucional da Universidade Estadual do Paraná (Unespar, 2018). Nesse sentido, uma das metas da Instituição, ao apresentar seu Plano de Objetivos, Metas e Ações do PDI para o período de 2018 a 2022, é "estimular e orientar os processos de internacionalização nas atividades de ensino, pesquisa e extensão com base na Política de Internacionalização da UNESPAR", visando "promover atividades de aprimoramento linguístico à comunidade acadêmica para ampliação ao acesso à internacionalização da UNESPAR, com ênfase na América Latina e Caribe" e "estimular a internacionalização da produção acadêmica com a participação em eventos internacionais, publicações estrangeiras e apresentação de trabalhos", abrangendo, principalmente, os países latino-americanos (Unespar, 2018, p. 64). Assim, a instituição objetiva, por meio da integração de suas ações, "em parceria com as Pró-Reitorias, apoiar o intercâmbio cultural, científico e tecnológico de discentes, docentes e agentes universitários promovendo a mobilidade física e virtual, bem como a internacionalização da gestão universitária, do ensino de graduação e pósgraduação, da pesquisa" (Unespar, 2018, p. 194). Trata-se de uma proposta da universidade, que propicia oportunidades para o desenvolvimento de práticas formativas e sociais.

Ademais, ao longo de nossa experiência enquanto professora formadora e pesquisadora, temos constatado aspectos lacunares referentes à leitura e escrita envolvendo dificuldades tanto em relação à produção de textos científicos (Dolz; Gagnon; Decandio, 2010) para fins de apresentação e/ou publicações em eventos e/ou periódicos internacionais, quanto à compreensão das concepções de letramento acadêmico, conforme mostram algumas Iniciativas de Leitura e Escrita no Ensino Superior $(\text { ILEES })^{2}$ que têm sido realizadas no Brasil e na América Latina. Isso aponta para a possível necessidade de uma maior preparação dos estudantes universitários para participar não somente do seu mundo acadêmico e científico, mas também de oportunidades relacionadas à internacionalização oferecidas pela universidade, tais como mobilidade, formas de intercâmbio, participações em eventos científicos internacionais e publicação de resumos ou artigos científicos em periódicos internacionais. Com isso, entendemos tal perspectiva como sendo necessária à formação humana, social e

\footnotetext{
1 Este trabalho vincula-se a um projeto de pesquisa em desenvolvimento, intitulado "Letramento acadêmico na pós-graduação: uma perspectiva necessária", na Unespar - Campus de Campo Mourão (PR), bem como ao Grupo de Pesquisa "Linguagem, Desenvolvimento, Educação e suas Relações" (LIDERE - CNPq), por nós coordenado, nesta mesma instituição e ao "Grupo de Pesquisa Letramentos Acadêmico-Científicos e Estudos da Linguagem" (LACEL - Unespar/CNPq). E, ainda, este trabalho vincula-se a um projeto de pesquisa maior, submetido ao edital de Bolsas em Produtividade em Pesquisa do Conselho Nacional de Desenvolvimento Científico e Tecnológico (CNPq), em desenvolvimento no triênio 2019-2021, intitulado "Ações de didatização de gêneros em prol de letramentos acadêmicos", em colaboração com diferentes Instituições de Ensino Superior (IES), proposto e organizado pelo Grupo de Pesquisa "Linguagem e Educação" (LILA UEL/Unespar/UTFPR/IFPR/Unicentro), dos quais fazemos parte, da Universidade Estadual de Londrina (UEL), coordenados pela Profa. Dra. Vera Lúcia Lopes Cristovão, bolsista de Produtividade em Pesquisa do CNPq.

2 Trata-se de um projeto de pesquisa realizado no Brasil e na América Latina, sob a coordenação do Prof. Dr. Charles Bazerman, com o objetivo de identificar as iniciativas de ensino e pesquisa em leitura e escrita realizadas no Ensino Superior do Brasil, a fim de investigar as possíveis transformações no panorama de letramento acadêmico nas universidades.
} 
profissional, assim como ao desenvolvimento intelectual, acadêmico e científico dos estudantes do Ensino Superior.

Por essas razões, considerando a universidade como um espaço social que permite esta formação e este desenvolvimento, por meio das quais o estudante tem o direito e o dever de desenvolver suas capacidades de leitura e escrita, tomando a perspectiva dos letramentos acadêmicos com vistas à internacionalização como fundamental para a sua formação enquanto sujeitos inseridos em diferentes contextos sócio-históricos e culturais, este nosso estudo justifica-se na medida em que pode contribuir tanto para uma compreensão mais ampliada acerca do tema proposto quanto para a identificação de aspectos para o desenvolvimento da leitura e da escrita no Ensino Superior. Tal temática tem sido crescente nas universidades brasileiras e paranaenses (Morosini, 2011; Silva; Lousada, 2014), o que tem gerado novas demandas linguísticas para a comunidade acadêmica. Com isso, esperamos que este trabalho possa contribuir para uma discussão em torno do processo de internacionalização pelo viés dos letramentos acadêmicos, que permeia os estudos no contexto universitário, possibilitando um maior envolvimento e engajamento de professores/pesquisadores e estudantes no Ensino Superior no desenvolvimento de práticas formativas e produção de trabalhos acadêmicos.

Assim, a fim de promover a reflexão e o debate social do tema proposto neste artigo, tomamos os seguintes questionamentos como norteadores da discussão proposta: I) Em quais aspectos podem se articular as perspectivas dos letramentos acadêmicos e de internacionalização no contexto do Ensino Superior? II) As atividades propostas e descritas, bem como as produções de texto dos professores em formação permitem aos futuros professores de línguas estabelecerem relações entre os letramentos acadêmicos e a internacionalização?

Se as questões mencionadas parecem difíceis de serem respondidas é porque ainda há lacunas tanto no processo de internacionalização quanto no dos letramentos acadêmicos, daí a importância de serem discutidas e ressignificadas. A nosso ver, tais reflexões e a discussão proposta, assim como as críticas, permitem um debate social que nos permitem reorganizar a Educação Superior em relação às temáticas apresentadas.

Quanto à organização textual, este texto foi sistematizado pelas seguintes partes constitutivas, a saber: a) fundamentação teórica norteadora de nosso estudo; b) metodologia por meio da qual apresentamos um trabalho desenvolvido com dados obtidos e analisados; c) discussão dos resultados; e, d) as considerações finais.

\section{Princípios norteadores}

Partindo do papel social das políticas de internacionalização e das políticas linguísticas voltadas para avanços e desafios nesta área, há que se considerar o trabalho desenvolvido pela Universidade Estadual do Paraná (Unespar), contexto este no qual me insiro profissionalmente, que, desde seu processo de credenciamento, em 2012, ao produzir Plano de Objetivo, Metas e Ações, quando seu Projeto Político Institucional (PPI) sofreu atualização e reformulação. Momento este em que as políticas 
de internacionalização eram elaboradas com base nas ações já em curso na Unespar, sendo que a instituição necessitava somente de sistematização em forma de documentos referentes à Política (Unespar, 2018). Conforme consta no documento do Plano de Desenvolvimento Institucional (PDI), referente aos anos de 2012 a 2016 da instituição (Unespar, 2018, p. 34), "buscou nortear as principais ações do período de organização inicial e de sua instalação", apresentando objetivos institucionais para a instituição, como "ações prioritárias e continuadas" com vistas à concretização da universidade, dentre os quais, destacamos:

c) Participar, em nível internacional, nacional, estadual e local, de fóruns de discussão e definição de políticas públicas no âmbito da inclusão social e da produção e difusão da ciência, da arte e da cultura, buscando sempre estruturar a participação discente.

[...]

p) Criar condições para estimular e fortalecer a pesquisa pelo incentivo ao desenvolvimento de programas inovadores, o intercâmbio com instituições nacionais e internacionais, a crescente qualificação de pesquisadores e grupos de pesquisa, bem como a divulgação do conhecimento produzido.

[...]

s) Promover uma inserção qualificada instituição no panorama acadêmico nacional e internacional, pela difusão da sua produção científica, técnica e artística (Unespar, 2018, p. 35).

Assim, com o credenciamento da Unespar, pelo Decreto Estadual n. 9538, de 05 de dezembro de 2013, a internacionalização passou a ser um dos aspectos fundamentais para o desenvolvimento da instituição e o cumprimento de sua Missão. Além disso, conforme apresentado no PDI da instituição (Unespar, 2018, p. 49), "para o período de 2018 a 2022, a Unespar sistematizou 47 metas institucionais, que contemplam os eixos e as dimensões ${ }^{3}$ referenciadas pelo SINAES" (Sistema Nacional de Avaliação da Educação Superior), dentre as quais destacamos as seguintes:

26. Implantar programas de internacionalização e extensão e cultura, com ênfase nos países Latino-americanos.

$[\ldots]$

32. Implantar as diretrizes da política de internacionalização da UNESPAR, priorizando ações de integração com Universidades e outras instituições, preferencialmente da América Latina e Caribe (Unespar, 2018, p. 49-50).

No que tange a algumas metas mais específicas, o Eixo 3 proposto pelo documento (Unespar, 2018, p. 61), referente a Políticas Acadêmicas, apresenta a meta 16, "Criar e implantar atividades de extensão e cultura que contribuam para a internacionalização da UNESPAR" e, dentro desta meta, o documento destaca a ação 26 , "Implantar programas de internacionalização de extensão e cultura, com

${ }^{3}$ Segundo o documento do PDI da instituição (UNESPAR, 2018, p. 48), "em 2014, estas dimensões foram reorganizadas em 5 eixos avaliativos, aqui destacados: Eixo 1 - Planejamento e Avaliação Institucional: considera a dimensão 8 do SINAES (Planejamento e Avaliação) [...]; Eixo 2 - Desenvolvimento Institucional: contempla as dimensões 1 (Missão e o Plano de Desenvolvimento Institucional) e 3 (Responsabilidade Social da Instituição) do SINAES; Eixo 3 - Políticas Acadêmicas: abrange as dimensões 2 (Políticas para o Ensino, Pesquisa e Extensão), 4 (Comunicação com a Sociedade) e 9 (Políticas de Atendimento aos Discentes) do SINAES; Eixo 4 - Políticas de Gestão: compreende as dimensões 5 (Políticas de Pessoal), 6 (Organização e Gestão da Instituição) e 10 (Sustentabilidade Financeira) do SINAES; Eixo 5 - Infraestrutura Física: contempla a dimensão 7 (Infraestrutura Física) do SINAES". 
ênfase nos países latino-americanos", apontando os seguintes objetivos: "Desenvolver atividades voltadas à pesquisa e à produção cultural e ao intercâmbio de ações extensionistas e artístico-culturais com a América Latina; Apoiar a pactuação de termos de cooperação nas diferentes áreas, entre as universidades e órgãos internacionais." Isso evidencia a relevância do papel social de uma instituição pública em desenvolvimento inserida em contexto sócio-histórico mais amplo de uma sociedade também em desenvolvimento que muito pode se beneficiar por meio de programas de internacionalização, bem como de práticas educacionais e formativas que também podem contribuir para os avanços neste âmbito.

Ademais, conforme consta no PDI da instituição (Unespar, 2018, p. 142), a Unespar sistematizou a Política Institucional de Internacionalização a partir de um documento "que apresenta um conjunto de princípios e objetivos que visam à implantação ou adaptação de ações institucionais para a promoção, fomento e consolidação do processo de internacionalização na universidade". O documento ainda apresenta a seguinte defesa:

De acordo com a Política aprovada, a internacionalização do ensino superior é entendida como um compromisso institucional, transversal e abrangente, que integra a dimensão intercultural e internacional na cultura e na educação, e os valores, práticas e estratégias institucionais com referencialidade e comprometimento social.

Ainda, compreende-se por dimensão internacional o intercâmbio de conhecimentos; a criação de redes colaborativas com instituições congêneres no exterior e no país; a mobilidade de professores, agentes universitários e estudantes e os programas e projetos de ensino, pesquisa, extensão e cultura internacionais (Unespar, 2018, p. 142).

Com isso, corroboramos a proposta de internacionalização da Unespar e, como professora formadora e pesquisadora inserida neste contexto, proponho uma discussão acerca da articulação entre a internacionalização e a perspectiva dos Letramentos Acadêmicos, uma vez que pode contribuir para o desenvolvimento dos estudantes e professores em formação no âmbito da Educação Superior pela disseminação de seus trabalhos acadêmicos e científicos tanto em nível nacional quanto internacional, a fim de que possamos lidar com seus avanços e desafios.

Assim, tomando por base alguns estudos acerca da temática proposta sobre os letramentos acadêmicos no Ensino Superior (Lea; Street, 1998; Jones; Turner; Street, 1999; Fischer, 2008; Fiad, 2011; Morosini, 2011; Bork et al., 2015; Silva; Lousada, 2014), visamos a promover uma discussão sobre os aspectos que podem permear a formação acadêmica e científica de nossos estudantes universitários com vistas a sua participação nas oportunidades oferecidas pela Universidade no que tange à internacionalização, como a mobilidade acadêmica e as apresentações em eventos científicos nacionais e/ou internacionais, além de publicações em periódicos científicos também nacionais ou internacionais. Pois, como consta no Documento de Área, Letras e Linguística, da CAPES (Brasil, 2016, p. 26-27), acerca das considerações e definições sobre internacionalização/inserção internacional,

A Área de Letras e Linguística considera que sua internacionalização tem por finalidade a cooperação com instituições e centros de pesquisa no exterior, em um patamar de 
paridade internacionalmente da produção de conhecimento, dando contribuição efetiva nessa produção e, ao mesmo tempo, obtendo ganhos de qualidade nos diálogos entre pares (Brasil, 2016, p. 26-27).

Para tanto, pautamos nossos estudos na concepção de letramentos acadêmicos que abrange o contexto universitário que possa contribuir com práticas sociais e formativas para o desenvolvimento acadêmico e científico no Ensino Superior. Primeiramente, há que se considerar que, conforme explicitam Bork et al. (2014, p. 3),

As instituições educacionais apresentam uma variedade de abordagens e cenários específicos, os quais devem levar em conta as diferentes histórias das comunidades acadêmicas. Bazerman et al. (2010, Prefácio) afirmam que "enquanto o interesse na atividade de escrita é algo global, as respostas são locais". Daí a relevância de projetos de pesquisa que busquem compreender o estado atual da área nas diferentes realidades, levando em consideração as estruturas, as ideologias e as políticas que regem e fundamentam os cursos universitários de cada país.

Partindo de tais princípios, entendemos os letramentos acadêmicos como uma perspectiva sócio-histórico-cultural, apoiada nos denominados Novos Estudos do Letramento 4 (Street, 1984; Barton; Hamilton, 1998; Gee, 1996; Fischer, 2007). Segundo outros autores (Gee, 1996; Lankshear et al. 2002), tais estudos do letramento tomam essa prática como processos socioculturais muito mais que estados ou eventos cognitivos internos. De acordo com Dionísio (2007, p. 26), a perspectiva do letramento refere-se a um "conjunto flexível de práticas culturais definidas e redefinidas por instituições sociais, classes e interesses públicos em que jogam papel determinante as relações de poder e de identidades construídas por práticas discursivas que posicionam os sujeitos" ao uso dos textos e tecnologias por meio das quais tais textos são veiculados. Daí a importância de pesquisarmos mais nesta área dos letramentos acadêmicos para que possamos desenvolver propostas de trabalho no Ensino Superior de modo a preparar os estudantes mais apropriadamente para as oportunidades do mundo científico visando ao seu desenvolvimento intelectual e profissional por meio de práticas letradas (Dias; Mont'Alverne, 2020).

Nesse sentido, Gee (1996) ainda caracteriza essa perspectiva como sociocultural, que envolve um conjunto de práticas sociais por meio do uso de diferentes formas de linguagem em uma única ou diferentes culturas, autorizando, com isso, a conceituação do letramento em uma versão plural, daí denominada de letramentos. Segundo Fischer (2007, p. 24), este conceito "tem sido refinado", especialmente no Brasil, "em virtude de novas modalidades de práticas sociais envolvendo leitura e escrita". Nesse sentido, tomando por base os estudos de Soares (2000, 2003, 2004), Fischer (2007, p. 24) refere-se à autora como "uma das precursoras dos estudos do letramento no Brasil", ressaltando que o termo apareceu em nosso país em meados dos anos 80 , sendo denominado, "ao mesmo tempo de illetrisme na França, litteracy nos Estados Unidos e Inglaterra e literacia em Portugal, distinguindo-se do fenômeno da alfabetização".

${ }^{4}$ Em inglês, New Literacy Studies. 
No Brasil, os estudos de letramento começaram a partir da década de 80 (Kato, 1986; Kleiman, 1995; Rojo, 2009; Kleiman; Matencio, 2005; entre outros). Segundo Kleiman (2005, p. 21), tal perspectiva "abrange o processo de desenvolvimento e o uso dos sistemas da escrita nas sociedades, ou seja, o desenvolvimento histórico da escrita refletindo outras mudanças sociais e tecnológicas, como a alfabetização universal, a democratização do ensino, o acesso às fontes aparentemente ilimitadas de papel, o surgimento da internet" (Kleiman, 2005, p. 21). Os diferentes usos e descobertas tecnológicas têm promovido o desenvolvimento de novas práticas de letramento em diferentes contextos sociais, envolvendo, de acordo com Marcuschi (2003, p. 25), "as mais diversas práticas da escrita (nas suas variadas formas) na sociedade", afirmando que "Letrado é o indivíduo que participa de forma significativa de eventos de letramento e não apenas aquele que faz um uso formal da escrita". Com isso, diferentes desdobramentos conceituais foram sendo criados e com diversas funções a fim de atender necessidades também distintas na sociedade. Assim, tomamos a concepção de letramento para além da concepção de alfabetização (Conceição, 2013), partindo do princípio que o letramento, vinculado à concepção do trabalho com a linguagem como prática social, está relacionado ao agir integrado a diferentes situações de comunicação em que o indivíduo possa estar inserido nos diversos contextos sociais em que vive.

Ademais, no que diz respeito à relação entre escrita, letramento(s) e gêneros textuais, Araújo e Bezerra (2013, p. 9), defendem que as relações humanas ocorrem por meio de textos, os quais são organizados em gêneros, que circulam em uma determinada "comunidade linguística e exigem a aquisição de habilidades de escrita por partes desses indivíduos, isto é, letramento(s), ou a condição letrada para determinados fins". Nessa perspectiva, tomando os novos conceitos de letramento propostos por Lea e Street (2014), a escrita do estudante universitário pode ser entendida em três diferentes aspectos, a saber: a habilidades de estudo, a socialização acadêmica e o letramento acadêmico. O primeiro aspecto refere-se à habilidade individual e cognitiva de leitura e escrita e ao conhecimento das estruturas formais da língua. O segundo envolve a socialização do aluno, pela responsabilidade do professor, no contexto universitário, relacionando-se com a aculturação de discurso e gêneros. Por fim, o letramento acadêmico relaciona-se aos seguintes pontos: identidade, poder, autoridade e produção de sentido. Trata-se da inserção do estudante na nova comunidade discursiva em que se insere, por meio de sua participação social, que constituirá suas práticas de letramento acadêmico e que poderão gerar a busca de novos conhecimentos para complementar os que já foram adquiridos.

Para atender a demanda de trabalhos envolvendo letramentos acadêmicos e a produção textual de gêneros relacionados à esfera acadêmica, alguns estudos têm sido desenvolvidos no sentido de ressignificar essa prática formativa (Motta-Roth; Hendges, 2010; Marinho, 2010; Fiad, 2011), tais como as obras Machado, Lousada e Abreu-Tardelli (2004a, 2004b, 2005a, 2005b, 2007) voltadas para a didatização de gêneros textuais acadêmicos. Tais pesquisas são pautadas na perspectiva do Interacionismo Sociodiscursivo (ISD) com foco no das capacidades de linguagem (Dolz; Pasquier; Bronckart, 1993; Schneuwly; Dolz, 2004). Além disso, Magalhães e Cristovão (2018) têm desenvolvido 
trabalhos referentes a letramento científico, gêneros textuais e ensino de línguas, contemplando tanto a língua materna quanto as línguas estrangeiras.

No que diz respeito às Capacidades de Linguagem tanto em relação ao trabalho com compreensão textual quanto com produção textual (Schneuwly; Dolz, 2004), referentes às Capacidades de Ação (CA) - elementos contextuais da situação de comunicação, considerando-se, produtor e receptor do texto e sua posição social, objetivo e conteúdo temático, local de produção e função social do texto -, Discursivas (CD) - organização textual e progressão textual, o tipo de informação que aparece no texto, a constituição do início do texto, seu desenvolvimento e sua finalização, emprego de conectivos ou operadores argumentativos -, Linguístico-Discursivas (CLD) operações de textualização como conexão e coesão nominal e verbal, mecanismos enunciativos de gerenciamento de vozes e modalização, construção de enunciados, oração e período, escolha de itens lexicais, e referências pronominais (Cristovão, 2007, p. 13) - e de Significação (CS), proposta mais recentemente por Stutz e Cristovão (2011) e Cristovão (2013), referente à atividade geral, a qual possibilita a construção de sentido entre textos a partir de representações e/ou conhecimentos acerca das práticas sociais já instaladas, envolvendo os contextos ideológico, histórico, sociocultural, econômico, entre outros, bem como esferas de atividade, atividades praxiológicas em interação com conteúdos temáticos de diferentes experiências humanas e suas relações com atividades de linguagem.

\section{Metodologia e resultados em construção}

No que se concerne à organização metodológica, tomamos por base a sistematização de procedimentos referentes aos três questionamentos norteadores da discussão proposta neste estudo, tendo como ponto central o trabalho de leitura e escrita com foco no gênero de texto Abstract, realizado em um curso de licenciatura dupla Português-Inglês, na disciplina de Língua Inglesa. Trata-se de um trabalho inicial voltado para a perspectiva dos letramentos acadêmicos.

No que tange ao tratamento dos dados, pautamos nossos estudos na perspectiva teóricometodológica do ISD (Bronckart, 2007) ao tratar das condições de produção dos textos, considerando o emissor: a pessoa física que produz o texto; o receptor: a(s) pessoa(s) física(s) que recebe $(\mathrm{m})$ o texto; o lugar de produção do texto; o momento de produção: o tempo concreto da produção do texto; o enunciador: o papel social do emissor naquela situação específica; o destinatário: o papel social do receptor naquela situação específica; o lugar social: a formação social do lugar onde o texto é produzido; e, o objetivo: o efeito que se quer produzir sobre o destinatário.

Para as análises, ancoramos nosso estudo nos elementos constitutivos do gênero de texto Abstract, tomando por base as capacidades de linguagem mobilizadas nestes elementos, conforme 0 quadro 1. Além disso, consideramos os estudos de Motta-Roth et al. (1999) e Ramos (2004) e MottaRoth et al. (1999, p. 111), ao ressaltar que um Abstract resume um artigo de pesquisa científica, 
apresentando "diferentes partes do estudo, os quais geralmente incluem introdução, metodologia, resultados e conclusão"5.

Quadro 1: Elementos ${ }^{6}$ constitutivos do gênero de texto Abstract

\begin{tabular}{|l|l|}
\hline \multicolumn{1}{|c|}{ Elementos constitutivos do gênero de texto Abstract } & \multicolumn{1}{|c|}{$\begin{array}{c}\text { Capacidades de linguagem } \\
\text { a serem mobilizadas }\end{array}$} \\
\hline 1. Contexto/Introdução & \multirow{2}{*}{ CS, CA, CD, CLD ${ }^{7}$} \\
\hline 2. Problema/Introdução & \\
\hline 3. Objetivo/Introdução & \\
\hline 4. Teoria norteadora, com autores e data de referência & \\
\cline { 1 - 2 } $\begin{array}{l}\text { 5. Metodologia (instrumentos de coleta de dados e } \\
\text { procedimentos de análise) }\end{array}$ & \\
\hline 6. Resultados & \\
\hline 7. Conclusão &
\end{tabular}

Fonte: Dados da pesquisa.

Quanto aos participantes desta investigação, desenvolvemos um estudo a partir de um trabalho realizado na disciplina de Língua Inglesa de um curso de graduação, Letras Português/Inglês, de uma universidade pública do interior do Estado do Paraná, com um grupo constituído por 13 estudantes, os quais permitiram a realização de um estudo acerca deste trabalho realizado em sala de aula.

No que diz respeito ao desenvolvimento das aulas com foco no gênero de texto Abstract, primeiramente, apresentamos aos professores em formação alguns elementos de contexto de produção, relacionados às capacidades de ação (elementos contextuais), envolvendo suporte ou local de publicação, os elementos constitutivos do gênero Abstract, contemplando objetivo, problema, teoria e metodologia, resultados e conclusões, e que podem ser relacionados às capacidades de significação, de ação, discursiva e linguístico-discursiva. Em seguida, os participantes deste estudo tiveram contato com exemplos de uso da língua inglesa no que tange aos elementos constitutivos do gênero em foco para, então, ler e reconhecer alguns exemplos do gênero Abstract.

Após trabalharmos atividades de compreensão deste gênero de texto, em que os professores em formação deveriam reconhecer seus elementos constitutivos, receberam uma consigna para a produção escrita de um Abstract, que deveria ser relacionada a um de seus projetos de pesquisa, desenvolvidos em seu curso de graduação, seguindo a orientação fornecida pela professora formadora, conforme mostra o quadro 2.

\footnotetext{
${ }^{5}$ A tradução original desta citação pode ser encontrada em Motta-Roth et al (1999, p. 111), como segue: "it shows the diferente parts of the study, which generally includes introduction, methodology, results and conclusion".

${ }^{6}$ Tais elementos foram utilizados como critérios de avaliação das produções escritas dos participantes.

${ }^{7}$ Consideramos estas Capacidades de Linguagem como sendo aspectos imbricados na constituição do gênero de texto em foco, uma vez que é necessário acessar os conhecimentos que cada uma contempla tanto para a compreensão quanto para a produção de texto ao atender aos elementos constitutivos do gênero Abstract mencionados no quadro 1.

${ }^{8}$ Embora apontemos este como um dos elementos constitutivos do gênero Abstract, consideramos que o uso de informações, referentes a autores e suas datas de referência em relação a determinadas perspectivas teóricas que possam fundamentar as pesquisas, em Resumos ou Abstracts pode depender dos critérios e exigências de diferentes periódicos, eventos e/ou programas de pós-graduação quanto às normas de publicação e disseminação científica.
} 


\section{Quadro 2: Consigna com orientações para a produção escrita de um Abstract}

Writing Activity with focus on Abstract Genre
INITL PRODUCTION
Considering the constituent elements of the Abstract genre we have been studying and
some discursive and linguistic-discursive or lexico-grammatical aspects related to this text
genre, write an Abstract about one of your research projects from 10 lines to 15 lines.

Fonte: Dados da pesquisa.

Em seguida, após realizarem a produção inicial de um Abstract sobre um dos projetos de pesquisa realizados ao longo do curso de Letras, revisamos e avaliamos os textos por eles produzidos e, na sequência, solicitamos aos professores em formação que fizessem a reescrita do texto. Para isso, enquanto professora formadora, utilizamos apontamentos, sugestões e questionamentos com o intuito de auxiliar os estudantes tanto em seu processo de revisão do texto para a reescrita quanto em uma reflexão sobre o atendimento ou não dos elementos constitutivos do gênero de texto Abstract. Para exemplificar o trabalho realizado, apresentamos um exemplo de escrita e reescrita de uma professora em formação inicial, conforme mostra o quadro 3.

\section{Quadro 3: Exemplo de uma produção escrita e de reescrita de um Abstract de uma professora} em formação inicial $\left(\mathrm{PFI}^{10}\right)$

\begin{tabular}{|c|c|}
\hline Produção inicial & Produção final \\
\hline $\begin{array}{l}\text { The work Alice in Wonderland (1865) Lewis Carroll } \\
\text { is one the big classic children's literature, charming } \\
\text { kids and adults from decades with your games of } \\
\text { words and meanings, dreams, simbols and one } \\
\text { word out of logic patterns. From this, the present } \\
\text { project aims to explore and discuss the symbology } \\
\text { used for Carroll in the construction of characters } \\
\text { Alice and Queen of Hearts from a nonsense } \\
\text { posture, that if lay as counterpoint to doe value } \\
\text { socio-historical cultural and ideological currents in } \\
\text { the context Victorian Age. It's hoped by this to } \\
\text { characterize the transgressive actions and postures } \\
\text { of the characters and analyze them as arising from } \\
\text { a nonsense creation that predict breaches in the } \\
\text { organization of social life. } \\
\text { Alice in Wonderland. Symbology. Nonsense. }\end{array}$ & $\begin{array}{l}\text { Abstract: The work Alice in Wonderland (1865) of } \\
\text { Lewis Carroll is one the big classic children's } \\
\text { literature, charming kids and adults for decades } \\
\text { with its games of words and meanings, dreams, } \\
\text { symbols and one world out of logic patterns. From } \\
\text { this, the present project aims to explore and } \\
\text { discuss the symbology used by Carroll in the } \\
\text { construction of the characters Alice, Cheshire and } \\
\text { Queen of Hearts from a nonsense posture, in order } \\
\text { to be a counterpoint to values the socio-historical } \\
\text { cultural and ideological currents in the Victorian } \\
\text { Age. It's expected through this study to } \\
\text { characterize the transgressive actions and postures } \\
\text { of the characters and analyze them as arising from } \\
\text { a nonsense creation that predicted breaches in the } \\
\text { organization of social life. From this work it was } \\
\text { possible to gain an understanding about the } \\
\text { nonsense genre, its importance for the } \\
\text { construction of meaning and how it presents } \\
\text { itself in the literary work. }\end{array}$ \\
\hline & $\begin{array}{l}\text { Keywords: Alice in Wonderland. Symbology. } \\
\text { Nonsense. }\end{array}$ \\
\hline
\end{tabular}

Fonte: Dados da pesquisa.

Os dados acima, primeiramente, nos revelam que, mesmo não tendo recebido instrução

\footnotetext{
9 Após a realização deste trabalho, constatamos um aspecto lacunar em relação à consigna para a produção escrita do Abstract, por isso, inserimos um reajuste, referente ao título e às palavras-chave, nesta consigna, que valerá para os próximos trabalhos a serem realizados por meio desta atividade. Tal reajuste constitui-se na seguinte instrução: "Remember to write the title and the key-words related to your study".

10 Deste momento em diante, utilizaremos a sigla PFI para Professores em Formação Inicial.
} 
específica sobre a inserção de palavras-chave, estas foram inseridas em ambas as produções, o que significa que a PFI ativou seus conhecimentos em relação aos conteúdos e exemplos de Abstracts estudados. No que tange à reescrita do texto em sua produção final, destacamos em negrito os termos que foram alterados e reformulados pela PFI de modo a tornar a produção final de seu texto mais apropriado de modo a atender a seus elementos constitutivos estudados ao longo das aulas. Assim, a $\mathrm{PFI}$ altera ou acrescenta alguns aspectos léxico-gramaticais ou linguístico-discursivos, conforme mostra a produção final, tais como: "by", "the", "to values the", "expected through this study", "predicted". Além disso, ao perceber a ausência de alguns destes elementos, a estudante acrescenta, ao final do texto, destacado em negrito, as informações que considera relevantes em relação a possíveis resultados e/ou conclusões do seu estudo em seu Abstract, o que mostra avanços após a implementação de atividades com leitura e produção escrita do gênero de texto em foco, possibilitando um maior domínio deste texto na esfera acadêmica e científica.

No que diz respeito aos novos conceitos de letramento propostos por Lea e Street (2014), mais especificamente, em relação à escrita do estudante universitário, três modelos devem ser considerados: a habilidades de estudo, a socialização acadêmica e o letramento acadêmico, há que se observar alguns avanços e limitações, que poderão ser ressignificadas em práticas formativas futuras. Assim, quanto às contribuições, após a descrição e análise de todas as atividades dispostas nesta discussão, constatamos que os resultados das atividades implementadas evidenciaram um desenvolvimento no que tange à habilidade individual e cognitiva de leitura e escrita, assim como quanto ao conhecimento das estruturas formais da língua, em relação ao gênero Abstract, conforme evidenciamos anteriormente. Além disso, no que se refere à socialização acadêmica, foi possível compartilhar alguns dos trabalhos entre os estudantes, porém, a nosso ver, ainda seria necessário a expansão de uma proposta de divulgação mais ampla por meio da qual outras pessoas dentre professores e estudantes do curso e/ou de outras áreas pudessem ter acesso às produções de texto realizadas, o que não foi possível no momento da implementação. Em relação ao terceiro modelo proposto por Lea e Street, o letramento acadêmico, envolvendo identidade, poder, autoridade e produção de sentido, quando a PFI apresenta em sua produção final estes resultados/conclusões "From this work it was possible to gain an understanding about the nonsense genre, its importance for the construction of meaning and how it presentes itself in the literary work", concluímos que a professora em formação ressignifica sua identidade ao acrescentar as possíveis contribuições de sua pesquisa, demonstrando, com isso, maior poder e autoridade enquanto estudante acadêmica, bem como uma maior produção de sentido, no que se refere ao desenvolvimento de sua produção inicial para a final. Com isso, os resultados desta produção mostram que, ao avançar na realização deste trabalho, a PFI demonstra uma maior preparação para aproveitar as oportunidades que possam aparecer quanto ao processo de internacionalização no contexto acadêmico e universitário.

Quanto às análises das produções iniciais e finais dos professores em formação, de um modo geral, primeiramente, sistematizamos os dados a partir de uma síntese do atendimento aos elementos 
constitutivos do gênero de texto Abstract tanto na produção inicial quanto na final, conforme apresenta o quadro 4.

Quadro 4: Síntese do atendimento aos elementos constitutivos do gênero de texto Abstract
\begin{tabular}{|l|c|}
\hline Elementos constitutivos do gênero de texto Abstract & $\begin{array}{c}\text { Atendimento dos PFI }{ }^{11} \text { aos } \\
\text { elementos constitutivos do } \\
\text { Abstract }\end{array}$ \\
\hline 1. Contexto & 9 \\
\hline 2. Problema & 5 \\
\hline 3. Objetivo & 12 \\
\hline 4. Teoria & 10 \\
\hline $\begin{array}{l}\text { 5. Metodologia (instrumentos de coleta de dados e } \\
\text { procedimentos de análise) }\end{array}$ & 12 \\
\hline 6. Resultados & 8 \\
\hline 7. Conclusão & 4 \\
\hline
\end{tabular}

Fonte: Dados da pesquisa.

Os dados obtidos por meio desta experiência de ensino e aprendizagem de língua inglesa, ilustrados no quadro acima, nos indicam algumas lacunas ${ }^{12}$ que ainda precisam ser trabalhadas na perspectiva dos letramentos acadêmicos em relação à constituição do gênero de texto estudado no âmbito da esfera acadêmica e científica. Isto nos aponta para a necessidade de desenvolvermos mais estudos, pesquisas e práticas formativas que possam contribuir para avanços nesta área, bem como no contexto específico do trabalho realizado. No entanto, dos 13 estudantes participantes deste estudo, a maioria demonstrou atender a 5 dos 7 elementos constitutivos do gênero de texto em foco, como mostra o quadro 4. Assim, 9 estudantes atenderam às informações relacionadas ao contexto, 12 apresentaram objetivo do seu estudo, 10 estudantes fizeram referência à perspectiva teórica norteadora de suas pesquisas, 12 explicitaram os procedimentos metodológicos e 8 evidenciaram os resultados de seus estudos. E ainda, no que concerne aos conceitos de letramento propostos por Lea e Street (2014), como já mencionado anteriormente, os três modelos, como a habilidade de estudo, a socialização acadêmica e o letramento acadêmico, a síntese dos dados acima evidencia contribuições quanto à primeira categoria, uma vez que houve avanços quanto ao acréscimo de informações e produção de sentido. No entanto, há que se considerar a necessidade de se expandir as práticas formativas para além do contexto de sala de aula a fim de que possa atingir os outros modelos propostos pela perspectiva dos letramentos acadêmicos. Daí a importância de se explorar a potencialidade de propostas como esta, envolvendo o trabalho com a escrita, revisão e reescrita com vistas ao processo de internacionalização. Em outras palavras, a exposição das produções dos estudantes de modo a compartilhar as informações e os conhecimentos produzidos, como apresentação de trabalhos a outros colegas do curso ou de outras áreas ou ainda pela participação em eventos na língua estrangeira estudada, pode contribuir para uma maior preparação tanto para os letramentos acadêmicos quanto

\footnotetext{
11 Número de professores em formação inicial (PFI) que atenderam aos elementos constitutivos do gênero de texto Abstract em sua produção escrita.

12 Isto se aplica ao contexto específico deste estudo, que é bastante restrito, e, por essa razão, não pode ser generalizado.
} 
para o processo de internacionalização a partir de oportunidades que podem surgir no âmbito acadêmico e profissional.

E ainda, em uma atividade avaliativa referente a uma compreensão de texto com foco no gênero Abstract, inserimos uma pergunta acerca das possíveis contribuições do texto lido para o processo de formação acadêmica e profissional, sobre possíveis contribuições do gênero de texto Abstract para a própria formação profissional, a saber: "Did the contente of the Abstract above contribute to your teacher education process and academic literacy? Why? Write this question in English". Para a discussão das análises desta consigna e dos possíveis resultados, ressaltamos algumas das percepções dos professores em formação participantes deste estudo por atenderem a esta proposta de discussão, conforme os excertos a seguir.

PFI 1 - I consider the abstract a good genre to work in the graduation course because weneed to do our researches or our future researches, so, it is an essential genre for this academic context.

PFI 2 - In my opinion, from the study carried out in the class with the abstract genre, I learned how to write an abstract and what it must contain and its importance in the academic world.

PFI 3 - Yes. Because this content was very important for the process education. With this content, we learned to produce an academic abstract and also teach it in a school.

PFI 4 - Yes, it contributed because it is important for us to understand the differences between an abstract in English and a summary in Portuguese, especially because we are academics, we will make use it in our professional lives.

PFI 5 - Yes, before studying abstract I thought that they were the English version of the "resumo", and now I know they're not. I also learned the structure and composition of the abstract so I think that the content helped me and contributed for my studies.

PFI 6 - In my opinion, the abstract contributed to my education process because I learned many things that I didn't know [...], I learned about some aspects to contribute to my development as a teacher.

No que se refere ao questionamento acima, feito aos estudantes, sobre a contribuição dos conteúdos para a formação dos professores e seu processo de letramentos acadêmicos, os dados, destacados em negrito nos referidos excertos, permitiram-nos identificar alguns aspectos como resposta e justificativa a tal questionamento, tais como: necessidade de desenvolver pesquisas futuras; relevância do gênero estudado para o contexto acadêmico e o processo de formação docente inicial; aprendizagem da produção escrita de um Abstract, sua estrutura e composição, enfim, seus elementos constitutivos e sobre como ensiná-lo; importância do entendimento da diferença entre Abstract e Resumo Escolar; uso futuro do gênero Abstract em suas vidas profissionais; e, aprendizagem de muitas coisas as quais não se sabia. Tal constatação nos possibilita entender que, quanto à perspectiva dos letramentos acadêmicos, houve contribuições no sentido de preparar melhor o professor em formação no que tange as suas habilidades de estudo para a socialização acadêmica e o letramento acadêmico, ainda que esta prática necessite de uma maior consolidação, o que, ao mesmo tempo, a nosso ver, 
contribui para uma maior preparação do estudante para oportunidades de desenvolvimento acadêmico e profissional propiciadas pela política de internacionalização da instituição. Oportunidades estas que podem ocorrer por meio de propostas referentes à mobilidade, formas de intercâmbio, participações em eventos científicos internacionais e publicação de resumos ou artigos científicos em periódicos internacionais. Como iniciamos a discussão deste texto, trata-se de uma perspectiva necessária à formação humana, social e profissional, ao desenvolvimento intelectual, acadêmico e científico dos estudantes do Ensino Superior.

Enfim, os dados obtidos nos permitem entender a relevância social e a importância de um trabalho sistematizado no sentido de oportunizar um processo de ensino e aprendizagem, de formação docente inicial pelo viés dos letramentos acadêmicos com vistas à internacionalização, não somente para que o professor em formação possa se sentir melhor preparado para sua participação mais ampla e efetiva na esfera acadêmica e profissional, mas também para que possa articular os saberes necessários ao ensino de línguas e à aprendizagem de seus futuros alunos.

\section{Considerações finais}

As análises das atividades propostas e descritas, das produções de texto dos professores em formação, nos permitiram entender que é possível ressignificar nossas práticas formativas no sentido de avançarmos no que diz respeito à perspectiva dos letramentos acadêmicos aliada à política de internacionalização oferecida pela instituição.

Assim, retomando o primeiro questionamento norteador deste estudo, apresentado na introdução deste trabalho, referente aos aspectos nos quais podem se articular as perspectivas dos letramentos acadêmicos e de internacionalização no contexto do Ensino Superior, identificamos os seguintes: a relevância social do gênero de texto estudado para o contexto acadêmico e de formação inicial no qual os professores em formação se inserem e a aprendizagem dos elementos constitutivos do gênero Abstract para suas atuações em contextos profissionais futuros. Tais aspectos apontam para a necessidade de se ultrapassar os modelos de habilidades de estudo para além da socialização acadêmica, a fim de se atingir o letramento acadêmico articulando-se à necessidade de uma preparação mais efetiva para sua participação no processo de internacionalização oferecido pela política da universidade. Com isso, consideramos tais questões como fundamentais para o desenvolvimento profissional dos estudantes, assim como também para a ressignificação de práticas formativas que possam contribuir para uma maior articulação entre os pontos acima destacados.

Em relação ao segundo questionamento por nós proposto sobre se atividades propostas e descritas, bem como as produções de texto dos professores em formação, permitem aos futuros professores de línguas estabelecerem relações entre os letramentos acadêmicos e a internacionalização, entendemos que, a partir dos dados analisados, ainda que com possíveis limitações, houve uma compreensão por parte dos professores em formação acerca da importância de um trabalho dessa natureza para o seu desenvolvimento com vistas aos letramentos acadêmicos e a importância do seu engajamento no processo de internacionalização. No entanto, há que considerar

\section{3}


que, enquanto instituição, ainda estamos no início de um processo de internacionalização e que, por isso, há a necessidade da realização de outras práticas formativas e pesquisas no sentido de buscarmos aprimorar o processo de ensino, aprendizagem e de formação acadêmica e profissional dos estudantes pelo viés dos letramentos acadêmicos.

Enfim, embora tenhamos encontrado algumas lacunas no estudo proposto, esperamos que possa contribuir para a continuidade dos trabalhos com foco nos letramentos acadêmicos no Ensino Superior, bem como para a formação acadêmica, científica, intelectual e profissional de nossos estudantes, a fim de que possam usufruir e se beneficiar da política de internacionalização proposta pela universidade. Afinal, como Nogueira (2018) ressalta, tomando por base os estudos de Street (2010), em relação à produção escrita de artigos acadêmicos há quatro grandes grupos de dimensões escondidas, a saber: escrita da internacionalização, uso do inglês, publicação e demandas institucionais versus tempo. Por essas razões e, pelo fato de estarmos em um processo inicial de política de internacionalização, defendemos a necessidade da continuidade deste estudo e pesquisas posteriores no sentido de contribuirmos mais efetivamente com esta proposta de discussão, considerada por nós um debate inicial.

\section{Referências}

ARAÚJO, Camila Maria de; BEZERRA, Benedito Gomes. Letramentos acadêmicos: leitura e escrita de gêneros acadêmicos no primeiro ano do curso de Letras. Diálogos: Revista de Estudos Culturais e da Contemporaneidade, n. 9, p. 5-37, maio/jun. 2013.

BARTON, David; HAMILTON, Mary. Local literacy: reading and writing in one community. London; New York: Routledge, 1998.

BORK, Ana Valéria Bisetto. Mapeamento das iniciativas de escrita em língua materna na Educação Superior: resultados preliminares. Prolíngua, v. 9, n. 1, p. 2-14, 2015.

BRASIL. Documento de Área: Letras e Linguística. Brasília: CAPES, 2016.

BRONCKART, Jean-Paul. Atividade de linguagem, textos e discursos: por um interacionismo sociodiscursivo. São Paulo: EDUC, 2007.

CONCEIÇÃO, Rute Izabel Simões. Concepções de letramento e a relação entre a fala e a escrita na visão de professores de língua portuguesa em formação. In: GONÇALVES, Adair Vieira; BANZARIN, Milene (Orgs.). Interação, gêneros e letramento: a (re)escrita em foco. Campinas: Pontes Editores, 2013, p. 133-147.

CRISTOVÃO, Vera Lúcia Lopes. Modelos didáticos de gênero: uma abordagem para o ensino de língua estrangeira. Londrina: EDUEL,2007.

CRISTOVÃO, Vera Lúcia Lopes. Para uma expansão do conceito de capacidades de linguagem. In: BUENO, Luzia; LOPES, Maria Angela Teixeira; CRISTOVÃO, Vera Lúcia Lopes (Orgs.). Gêneros textuais e formação inicial: uma homenagem à Malu Matencio. Campinas: Mercado das Letras, 2013, p. 357-380.

DIAS, Rutineia Silva Oliveira; MONT' ALVERNE, Clara Roseane da Silva Azevedo. Letramento e a existência de práticas letradas no ambiente escolar. Revista Científica Multidisciplinar Núcleo do Conhecimento, v. 5, n. 6, p. 5271, 2020.

DIONíSIO, Maria de Lourdes. Educação e os estudos atuais sobre letramento. Perspectiva, v. 25, n. 1, p. 209-224, jan./jun. 2007.

DOLZ, Joaquim; GAGNON, Roxane; DECANDIO, Fabrício. Produção escrita e dificuldades de aprendizagem. Campinas: Mercado das Letras, 2010.

DOLZ, Joaquim; PASQUIER, Auguste; BRONCKART, Jean-Paul. L'acquisitiondesdiscours: emergence d'une compétence ou apprentissage de capacitéslangagièresdiverses. Etudes de Linguistique appliquée, n. 92, p. 23-37, 1993. 
FIAD, Raquel Salek. A escrita na universidade. Revista da ABRALIN, v. 10, n. 4, p. 357-369, 2011.

FISCHER, Adriana. A construção de letramentos na esfera acadêmica. 340f. Doutorado em Linguística pela Universidade Federal de Santa Catarina. Florianópolis, 2007.

FISCHER, Adriana. Letramento acadêmico: uma perspectiva portuguesa. Revista Acta Scientiarum, v. 30, n. 2, p. 177-187, jul./dez. 2008.

GEE, James Paul. Social linguistics and literacies: ideology in discourses. London; Philadelphia: The Farmer Press, 1996.

JONES, Carys; TURNER, Joan; STREET, Brian (Orgs.). Students writing in the university: cultural and epistemological issues. Amsterdam: John Benjamins, 1999.

KATO, Mary. No mundo da escrita: uma perspectiva psicolinguística. São Paulo: Ática, 1986.

KLEIMAN, Angela (Org.). Os significados do letramento: uma nova perspectiva sobre a prática social da escrita. Campinas: Mercado de Letras, 1995.

KLEIMAN, Angela; MATENCIO, Maria de Loudes Meirelles (Orgs.). Letramento e formação do professor: práticas discursivas, representações e construção do saber. Campinas: Mercado de Letras, 2005.

LANKSHEAR, Colin et al. Introduction. In: LANKSHEAR, Colin et al. Changing literacies. Philadelphia: Open University Press, 2002, p. 1-7.

LEA, Mary; STREET, Brian. Student writing in higher education: an academic literacies approach. Studies in Higher Education, v. 23, n. 2, p. 157-173, 1998.

LEA, Mary; STREET, Brian. O modelo de "letramentos acadêmicos": teoria e aplicações. Filologia e linguística Portuguesa, v. 16, n. 2, p. 477-493, jul./dez. 2014.

MACHADO, Anna Rachel; LOUSADA, Eliane; ABREU-TARDELLI, Lília Santos. Resumo. São Paulo: Parábola Editorial, 2004a.

MACHADO, Anna Rachel; LOUSADA, Eliane; ABREU-TARDELLI, Lília Santos. Resenha. São Paulo: Parábola Editorial, 2004b.

MACHADO, Anna Rachel; LOUSADA, Eliane; ABREU-TARDELLI, Lília Santos. Planejar gêneros acadêmicos. São Paulo: Parábola Editorial, 2005a.

MACHADO, Anna Rachel; LOUSADA, Eliane; ABREU-TARDELLI, Lília Santos. O resumo escolar: uma proposta de ensino do gênero. SIGNUM, v. 8, n. 1, p. 89-101, jun. 2005b.

MACHADO, Anna Rachel; LOUSADA, Eliane; ABREU-TARDELLI, Lília Santos. Trabalhos de pesquisa. São Paulo: Parábola Editorial, 2007.

MAGALHÃES, Tania Guedes; CRISTOVÃO, Vera Lucia Lopes. Letramento científico, gêneros textuais e ensino de línguas: uma contribuição na perspectiva do interacionismo sociodiscursivo. Raído, v. 12, n. 30, p. 52-72, jul./dez. 2018.

MARCUSCHI, Luiz Antonio. Da fala para a escrita: atividades de retextualização. São Paulo: Cortez, 2003.

MARINHO, Marildes. A escrita nas práticas de letramento acadêmico. Revista Brasileira de Linguística Aplicada, v. 10, n. 2, p. 363-386, 2010.

MOROSINI, Marília Costa. Internacionalização na produção de conhecimento em IES brasileiras: cooperação internacional tradicional e cooperação internacional horizontal. Educação em Revista, v. 27, n. 1, p. 93-112, 2011.

MOTTA-ROTH, Désirée. A importância do conceito de gêneros discursivos no ensino de redação acadêmica. Intercâmbio, v. 8, p. 119-128, 1999.

MOTTA-ROTH, Désirée; HENDGES, Graciela Rabuske. Produção textual na universidade. São Paulo: Parábola Editorial, 2010.

NOGUEIRA, Nara Nília Marques. Dimensões "escondidas" da internacionalização do ensino superior. Revista Brasileira de Linguística Aplicada, v. 18, n. 4, p. 951-982, 2018.

RAMOS, Rosinda de Castro Guerra. Gêneros textuais: uma proposta de aplicação em cursos de inglês para fins específicos. The ESPecialist, v. 25, n. 2, p. 107-129, 2004.

ROJO, Roxane. Letramentos múltiplos, escola e inclusão social. São Paulo: Parábola, 2009.

SCHNEUWLY, Bernardo; DOLZ, Joaquim. Gêneros orais e escritos na escola. Campinas: Mercado das Letras, 2004. 
SILVA, Emily Caroline da; LOUSADA, Eliane Gouvêa. O plano de estudos: um gênero textual acadêmico para pleitear intercâmbio. Horizontes, v. 32, n. 2, p. 73-87, jan./jun. 2014.

SOARES, Magda. Letramento: um tema em três gêneros. Belo Horizonte: Autêntica, 2000.

SOARES, Magda. Letramento e escolarização. In: RIBEIRO, Vera Magalhães (Org.). Letramento no Brasil. São Paulo: Global, 2003, p. 89-113.

SOARES, Magda. Letramento e alfabetização: as muitas facetas. Revista Brasileira de Educação, n. 25, p. 18-19, jan./abr. 2004.

STREET, Brian. Literacy in theory and practice. London: Cambridge University Press, 1984.

STREET, Brian. Dimensões escondidas na escrita de artigos acadêmicos. Perspectiva, v. 28, n. 2, p. 541-457, 2010.

STUTZ, Lidia; CRISTOVÃO; Vera Lucia Lopes. A construção de uma sequência didática na formação docente inicial de língua inglesa. Signum, v. 14, n. 1, p. 569-589, 2011.

UNESPAR. PDI - Plano de Desenvolvimento Institucional: 2018-2022. Paranavaí: Unespar, 2018. 